Article

\title{
Deep-Coverage MPS Analysis of Heteroplasmic Variants within the mtGenome Allows for Frequent Differentiation of Maternal Relatives
}

\author{
Mitchell M. Holland ${ }^{1, *}$, Kateryna D. Makova ${ }^{2}$ (D) and Jennifer A. McElhoe ${ }^{1}$ (iD \\ 1 Department of Biochemistry \& Molecular Biology, Forensic Science Program, Eberly College of Science, \\ Pennsylvania State University, University Park, PA 16802, USA; jam760@psu.edu \\ 2 Department of Biology, Eberly College of Science, Pennsylvania State University, University Park, \\ PA 16802, USA; kmakova@bx.psu.edu \\ * Correspondence: mmh20@psu.edu
}

Received: 1 January 2018; Accepted: 20 February 2018; Published: 26 February 2018

\begin{abstract}
Distinguishing between maternal relatives through mitochondrial (mt) DNA sequence analysis has been a longstanding desire of the forensic community. Using a deep-coverage, massively parallel sequencing (DCMPS) approach, we studied the pattern of mtDNA heteroplasmy across the mtgenomes of 39 mother-child pairs of European decent; haplogroups H, J, K, R, T, U, and X. Both shared and differentiating heteroplasmy were observed on a frequent basis in these closely related maternal relatives, with the minor variant often presented as $2-10 \%$ of the sequencing reads. A total of 17 pairs exhibited differentiating heteroplasmy (44\%), with the majority of sites $(76 \%$, 16 of 21) occurring in the coding region, further illustrating the value of conducting sequence analysis on the entire mtgenome. A number of the sites of differentiating heteroplasmy resulted in non-synonymous changes in protein sequence ( 5 of 21 ), and to changes in transfer or ribosomal RNA sequences (5 of 21), highlighting the potentially deleterious nature of these heteroplasmic states. Shared heteroplasmy was observed in 12 of the 39 mother-child pairs (31\%), with no duplicate sites of either differentiating or shared heteroplasmy observed; a single nucleotide position (16093) was duplicated between the data sets. Finally, rates of heteroplasmy in blood and buccal cells were compared, as it is known that rates can vary across tissue types, with similar observations in the current study. Our data support the view that differentiating heteroplasmy across the mtgenome can be used to frequently distinguish maternal relatives, and could be of interest to both the medical genetics and forensic communities.
\end{abstract}

Keywords: heteroplasmy; tissue differentiation; forensic science; next generation sequencing

\section{Introduction}

The advent of massively parallel sequencing (MPS) has paved the way for detailed analysis of mitochondrial (mt) DNA heteroplasmy in the fields of medicine [1,2], anthropology [3,4], and forensic science $[5,6]$. It has become increasingly clear that mutations in the human mtgenome are linked to a wide range of degenerative diseases, cancer, and aging [7-11], as the maternally inherited mtgenome codes for genes essential for the energy requirements of the cell, and for calcium buffering and sequestration. Given that mtDNA is present in hundreds to thousands of copies per cell, mutational events, deleterious or otherwise, typically pass through a heteroplasmic transition state [12]. Heteroplasmic variants migrate through a bottleneck in the female germline until fixation or elimination, and drift between and within somatic tissues through replicative segregation. The mechanism by which the variants become fixed in the germline is still poorly understood, but is essential for interpreting the clinical nature of resulting disease states. An empirically derived estimate 
of the size of the germline bottleneck in humans was calculated at $~ 30-35$ copies of the mtgenome [13]. In another study, a variable-size model was used to estimate the mean bottleneck at nine copies [14], further illustrating that the size and consistency of the bottleneck remains unresolved [15]. Nonetheless, the restricted nature of the bottleneck clearly explains the dramatic drift in heteroplasmic variant ratios observed in several previous studies, including forensic investigations [6,16-19].

The identification of Nicholas Romanov, the last Russian Tsar, is an example of the power of forensic mtDNA analysis when including the interpretation of heteroplasmy [17]. When considering the haplotype match between the presumed skeletal remains of Nicholas and the known remains of his brother, Georgji, the findings were 150 times more likely, but increased to approximately 375,000 times more likely when including the shared heteroplasmy. The ratio of cytosine to thymine at position 16169 of the mtDNA control region (CR) [20] was approximately 2:1 for Nicholas, but 0.7:1 for Georgji. The narrow bottleneck exhibited in the development and maturation of individual oocytes from their mother, Maria Feodorovna, Princess Dagmar of Denmark and Empress of Russia, resulted in a major haplotype change from 16169C (Nicholas) to 16169T (Georgji). The estimated percentage of the C-variant in Nicholas was $67 \%$, and $40 \%$ for Georgji; the former was verified through cloning experiments [21]. These findings illustrate the capacity of conventional Sanger-type sequencing (STS) to detect heteroplasmic variants that have reached at least $10-20 \%$ of the sequences in a DNA sample [22]. In addition, they emphasize that heteroplasmy is often shared by close maternal relatives when observed at higher levels. Contrary to this, apparent substitutions of one major haplotype for another have been observed between closely related individuals [23], illustrating that germline drift can be quite severe and further underscoring the weaknesses of STS for detecting low-level variants.

The transmission of heteroplasmic variants between maternal relatives is a relatively understudied area of mtDNA genetics when applying an MPS approach [13,24-26], including studies of twins [14] and centenarians [27]. A recent report on the analysis of mtgenomes from 194 mother-child pairs yielded no observations of differentiating heteroplasmy between the closely related individuals [28]. While 30 of the 194 pairs (15.5\%) exhibited heteroplasmy, the sites of heteroplasmy were shared between the relatives, with the major haplotype shifting to the other variant in four instances. The MPS approach chosen by the authors [29] was the driving force for the findings, as read coverage on a per nucleotide basis was low (approximately 650 reads), with a requirement of 40 reads of the minor variant. As a result, at best, the threshold for detection of minor variants was approximately 6\%. Despite this option, the authors set the reporting threshold at $10 \%$. This approach significantly reduced the number of heteroplasmic sites captured by the MPS technique, as a relatively large percentage of the population has heteroplasmy between $2-10 \%$; for example, more than $40 \%$ of the European population exhibits heteroplasmy within the CR alone, with approximately three quarters of the heteroplasmy between a frequency of $2-10 \%$ [30].

When assessing the transmission of heteroplasmy between maternal relatives using an MPS approach, two important considerations should be addressed. First, the depth of read coverage will dictate the sensitivity of detecting and resolving heteroplasmic sites. Ideally, a read depth of $>2000$ will allow for robust detection of variants at or below $2 \%[27,31]$. Second, the tissue type chosen for studies of both rates of heteroplasmy and maternal inheritance of heteroplasmic variants will have an impact on the findings, so should be carefully considered when conducting these experiments. For instance, it is known that rates of heteroplasmy are greater in buccal cells than blood [13], and that kidney, liver, and skeletal muscle exhibit high rates of heteroplasmy [32]. Therefore, when conducting experiments on peripheral blood, and using an MPS approach with low read depths and high reporting thresholds for heteroplasmy [28], it is expected that little differentiating heteroplasmy will be observed, suggesting that this approach would not be useful in a forensic or clinical setting.

In the current study, an optimized method of deep-coverage, massively parallel sequencing (DCMPS) was used to evaluate the pattern of heteroplasmy in the mtgenomes of blood and buccal cells collected from 39 mother-child pairs. A threshold of $2 \%$ was used for reporting minor sequence variants, and error assessments were employed to ensure the reliability of the reported data. Two cell types 
were collected from the 39 pairs to assess tissues specific correlations, and to confirm the presence of differentiating heteroplasmy through analysis of cells originating from a different germ layer. Overall, our findings add to the growing body of knowledge regarding the pattern and rate of heteroplasmy within the mtgenome and could be of interest to both the medical genetics and forensic communities.

\section{Materials and Methods}

\subsection{Samples and DNA Extraction}

A total of 78 buccal and blood samples (156 samples total) were collected from mother-child pairs under an approved protocol from the Human Subjects Protection Office of the Pennsylvania State College of Medicine (IRB \# 30432EP). The laboratory work conducted for this study was a collaborative effort between the Holland group (Forensic Science Program, Penn State University, University Park, PA, USA) and the Makova group (Biology Department, Penn State University, University Park, PA, USA). Collection of samples for the study, information about the study participants, and MPS data has been described previously [13,31]. The current study was a complete reanalysis of the data for the purposes of assessing the ability to differentiate maternal relatives. Extraction of DNA from buccal and blood cells was performed as described previously in Goto et al. [24].

\subsection{Long-Range Polymerase Chain Reaction}

The mtgenome was amplified using a long-range PCR approach with over-lapping 8.5 kilobase (kb) targets according to Goto et al. [24], and reported previously in [13,31]. In summary, the following oligonucleotide primer sets from Integrated DNA Technologies, Skokie, IL were used for amplification: 5'- GCGACCTCG-GAGCAGAAC-3' (L2817) and 5'- GTAGGCAGATGGAGCTTG TTAT-3' (H11570) for amplicon A, and 5'-CCACTGACATGACTTTCCAA-3' (L10796) and 5'-AGAATTTTTCGTTCGGTAAG-3' (H3370) [33] for amplicon B. One hundred nanograms (ng) of isolated genomic DNA (gDNA) was used as a template in a $50 \mu \mathrm{L}$ PCR reaction containing $2 \mu \mathrm{M}$ of each of the two primers, $200 \mu \mathrm{M}$ dNTP (PCR grade; Roche Applied Science, Indianapolis, IN, USA), 3 units of Expand High Fidelity PCR Enzyme (Roche Applied Science), 1X PCR buffer with $1.5 \mathrm{mM}$ $\mathrm{MgCl}$, and nuclease-free water (Teknova, Hollister, CA, USA). The PCR parameters included a $94^{\circ} \mathrm{C}$ soak for $2 \mathrm{~min}$; followed by 10 cycles of $94^{\circ} \mathrm{C}$ for $15 \mathrm{sec}, 62.3^{\circ} \mathrm{C}$ for $30 \mathrm{sec}$, and $68^{\circ} \mathrm{C}$ for $8 \mathrm{~min}$; followed by 30 cycles of $94{ }^{\circ} \mathrm{C}$ for $15 \mathrm{sec}, 62.3^{\circ} \mathrm{C}$ for $30 \mathrm{sec}$, and extension at $72{ }^{\circ} \mathrm{C}$ for $8 \mathrm{~min}$. The extension time was elongated by $5 \mathrm{sec}$ for each successive cycle during the last cycling phase. A final extension was performed at $72{ }^{\circ} \mathrm{C}$ for $7 \mathrm{~min}$. Amplifications were carried out in a GeneAmp PCR System 9700 (ThermoFisher Scientific, USA). The PCR products $(2 \mu \mathrm{L})$ were imaged by agarose gel electrophoresis to confirm successful amplification.

\subsection{MiSeq MPS}

All samples were sequenced on Illumina's (San Diego, CA, USA) MiSeq benchtop sequencer, using Nextera ${ }^{\circledR}$ XT (Illumina) sample preparation, and a 500-cycle reagent kit, and reported previously in [13,31]. In summary, samples were sequenced using paired 250 nucleotide reads, multiplexing 12, dual-indexed samples per run. Although the Nextera ${ }^{\circledR}$ XT kit reagents were used in sample preparation, the protocol followed was a combination of the protocols available for Nextera ${ }^{\circledR}$ XT and Nextera ${ }^{\circledR}$ DNA kits. The manufacturers recommended protocol for Nextera ${ }^{\circledR}$ XT was used with the exception of the bead normalization procedure. The bead normalization step streamlines library preparation for sequencing runs containing a large number of samples (i.e., multiplexing 96 samples), but each of the runs performed in this study contained 12 samples. Therefore, quantification and dilution of individual samples was a more efficient approach to normalizing the samples. Quantification and dilution is the method used in the Nextera ${ }^{\circledR}$ DNA protocol for normalization, so this protocol was followed for the remainder of the library preparation. The sequences reported in this paper were 
deposited previously [13] in the Sequence Read Archive (SRA), www.ncbi.nlm.nih.gov/sra (accession no. SRP047378).

\subsection{Data Analysis}

All sequence data generated in this project was mapped to the revised Cambridge Reference Sequence (rCRS; GenBank ID NC_012920.1) [34] using MiSeq Reporter (Illumina v2.1.43 and v2.2.29), which uses a Burrows-Wheeler Aligner (BWA) and the Genome Analysis ToolKit (GATK) for variant calling of single nucleotide polymorphisms (SNPs) and short indels. Secondary analysis was performed on the existing dataset using GeneMarker ${ }^{\circledR}$ High Throughput Sequencing (HTS) (GM-HTS; SoftGenetics, State College, PA, USA; v1.2.2) software [35]. The alignment algorithm in GM-HTS performs a Burrows-Wheeler [36] hash alignment based on spaced seeds (13 bases, ignore 1 base, and 13 more bases) and fills in gaps with dynamic programming. After alignment, a motif file (built-in or user-customized) can be applied to the reads. The motif file consists of a list of variant calls that are translated into an expected sequence. Each motif region is defined by a start and end nucleotide position and is inclusive, meaning that reads that do not span the entire region are trimmed. Alignment of reads spanning a defined motif region is adjusted to match the expected alignment pattern. For this exercise, FASTQ files were mapped to the rCRS using the following alignment options: customized motif file, $85 \%$ identity, and soft clipping at locations with three consecutive base pairs with a quality score $\leq 29$. Table report settings were as follows: input region nucleotide position (np) $1-16,569$, variant percentage $\geq 1 \%$ as the analytical threshold, variant allele coverage $\geq 40$, total coverage $\geq 200$, allele balance ratio $\leq 2.5$, and allele score balance $\leq 10$. A reporting threshold of $2 \%$ was used for calling heteroplasmic positions. The motif file, a simple text file containing phylogenetically correct sequence motifs that instructs the software which alignments are preferred by the user, contained 127 motifs that included those collected from the literature [37,38], as well as user-defined motifs based on new sequence patterns observed in the dataset. This process constituted a reanalysis of the dataset using a different software approach, with quality assessment of the data having been performed previously [13].

\subsection{Error and Coverage Assessment}

A conservative estimation of the substitution error rate for each base call (A, C, T, G) and base position $(1-16,569)$ across the mtgenome, was used to establish the level of background noise in the sequencing data; i.e., from the combined effects of library preparation, sequencing, and secondary alignment. The analysis was performed by evaluating the consensus statistic files for all samples ( $n=156$ samples) with no mutation filtering, and assuming any calls constituting less than or equal to $50 \%$ of the total reads at a given position were made in error. Since substitution errors are the main source of errors on the MiSeq [39,40], insertions and deletions, most of which occur in simple repeat sequences, were omitted from this analysis. The error assessment was done using a combination of the MacOS terminal emulator with the Unix shell Bash, version 3.2.57(1) [41], (Bash 2007) and RStudio, version 1.1.383 [42] (Team R 2016).

Due to a characteristic uneven distribution of coverage associated with MPS sequencing of the mtgenome, a depth of coverage assessment was completed to determine the proportion of nucleotides that could not be characterized at the $2 \%$ minor allele frequency threshold due to filtering parameters applied in the GM HTS software. In this study, the filter settings required a minimum of 40 variant calls for any alternative allele to be reported by the software. This means that a filter setting of 40 calls required a minimum coverage of 2000 reads to report calls at $2 \%$. The depth of coverage at each nucleotide position was taken from consensus statistic reports generated by GM HTS, prepared for upload using Terminal, and uploaded into RStudio for depth of coverage calculations. Note: contamination assessments were addressed previously [13]. 


\subsection{Haplogroup Generation}

Haplogroups were established using the collated major haplotype data and the Mitotool algorithm [43] incorporating Phylotree build 15 or 16 [44].

\subsection{Statistical Analysis}

Welch Two Sample $t$-tests were applied to evaluate the statistical significance of the heteroplasmy rate among shared, differentiating, and random sites of heteroplasmy, as well as a comparison of random heteroplasmy rates in mothers and children. All tests were conducted using RStudio.

\section{Results and Discussion}

\subsection{Shared Heteroplasmy}

A summary of the DCMPS results for the mother-child pairs can be found in Table 1, with additional details provided in Supplemental Tables S1-S3, including metadata associated with differentiating heteroplasmy (Table S2) and a comparison of shared, differentiating and random sites of heteroplasmy (Table S3). As a point of definition, shared heteroplasmy was considered when at least one of the two tissue types for both the mother and child of the pair shared the same site of heteroplasmy. Differentiating heteroplasmy was considered when one of the two family members had the same site of heteroplasmy in both buccal and blood samples, with the absence of the same site of heteroplasmy in the buccal and blood samples from the other family member. Lastly, random heteroplasmy was considered when sites were not replicated in the second tissue type of the same individual, and not observed in the other family member in a mother-child pair.

A total of 12 pairs (31\%, 12 of 39) exhibited shared heteroplasmy, at 14 distinct sites across the 16,569 nps of the mtgenome. One family unit (No. 6, Table 1; No. 15, Table S1) had three sites of heteroplasmy, two of which resulted in a primary haplotype change between the mother and child. Two of the three sites were located in the coding portion of the mtgenome (nps 3243 and 5539), while the third site was located in the CR (np 16192) that resulted in length-based heteroplasmy at position 16191. The frequency of heteroplasmy at the three sites ranged from $13.13-41.94 \%$ in all four samples (buccal and blood from both mother and child), indicative of moderate genetic drift.

Two of the 12 mother-child pairs exhibited shared heteroplasmy in three of the four samples collected. In one family unit (No. 4, Table 1; No. 6, Table S1), the child had heteroplasmy of $6.66 \%$ and $5.40 \%$ in buccal and blood samples, respectively, while the mother had $2.53 \%$ heteroplasmy in her buccal cells, with no detectable heteroplasmy in her blood. This is an expected finding, as the genetic drift observed during development of different tissue types can routinely impact the ability to detect heteroplasmic variants when the overall frequency of heteroplasmy in the individual is low, even when using an MPS approach [6]. In the second family unit (No. 7, Table 1; No. 16, Table S1), the mother had heteroplasmy at np 16093 towards the SNP (i.e., T16093C heteroplasmy), with 11.53\% heteroplasmy in buccal cells and $9.12 \%$ in her blood. The child exhibited 3.45\% heteroplasmy in buccal cells, with no detectable heteroplasmy in the blood sample. In addition, the direction of the heteroplasmy for the child was towards the reference sequence (i.e., T16093T), illustrating that the mother and child differed in their primary haplotypes at np 16093. This is another example of both the severe germline bottleneck, as well as the potential drift between tissues types that can be observed when comparing sequence from maternal relatives possessing heteroplasmy. 
Table 1. Shared heteroplasmy for 12 of the 39 mother-child pairs. Frequency of heteroplasmy at each nucleotide position (np) in percentage (\%), with the minor variant annotated as the letter after the np; i.e., A1656A (2.11\%) is heteroplasmy at np 1656, with the first $\mathrm{A}$ as the reference sequence and the second $\mathrm{A}$ as the minor variant at $2.11 \%$ of the reads. Underlined letters following the np of heteroplasmy indicate a primary haplotype change between the mother and child. In two instances, heteroplasmy was not detected (ND) in a sample.

\begin{tabular}{|c|c|c|}
\hline Mother-Child Pair & Sample Number & Shared Heteroplasmy \\
\hline \multirow[t]{4}{*}{1} & Mother-Bu (807) & A16183G (7.32\%) \\
\hline & Child-Bu (803) & A16183G (6.89\%) \\
\hline & Mother-Bl (M490) & A16183G (2.81\%) \\
\hline & Child-Bl (M490-C) & A16183G (2.46\%) \\
\hline \multirow[t]{4}{*}{2} & Mother-Bu (618) & $\mathrm{T} 16189 \mathrm{C}(7.74 \%)$ \\
\hline & Child-Bu (606) & $\mathrm{T} 16189 \mathrm{C}(11.07 \%)$ \\
\hline & Mother-Bl (M249) & $\mathrm{T} 16189 \mathrm{C}(2.81 \%)$ \\
\hline & Child-Bl (M249-C) & $\mathrm{T} 16189 \mathrm{C}(9.92 \%)$ \\
\hline \multirow[t]{4}{*}{3} & Mother-Bu (704) & $\mathrm{T} 6152 \mathrm{C}(7.23 \%)$ \\
\hline & Child-Bu (630) & $\mathrm{T} 6152 \mathrm{C}(16.37 \%)$ \\
\hline & Mother-Bl (M234) & $\mathrm{T} 6152 \mathrm{C}(5.04 \%)$ \\
\hline & Child-Bl (M234-C) & T6152C (16.48\%) \\
\hline \multirow[t]{4}{*}{4} & Mother-Bu (762) & T10873C (2.53\%) \\
\hline & Child-Bu (702) & $\mathrm{T} 10873 \mathrm{C}(6.66 \%)$ \\
\hline & Mother-Bl (M210) & ND \\
\hline & Child-Bl (M210-C) & $\mathrm{T} 10873 \mathrm{C}(5.40 \%)$ \\
\hline \multirow[t]{4}{*}{5} & Mother-Bu (729) & $\mathrm{A} 1656 \mathrm{~A}(2.11 \%)$ \\
\hline & Child-Bu (684) & A1656A (2.52\%) \\
\hline & Mother-Bl (M213) & A1656A $(2.77 \%)$ \\
\hline & Child-Bl (M213-C) & $\mathrm{A} 1656 \mathrm{~A}(2.68 \%)$ \\
\hline \multirow[t]{4}{*}{6} & Mother-Bu (1091) & 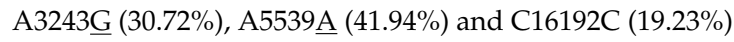 \\
\hline & Child-Bu (1111) & A3243A $(33.10 \%)$, A5539 $\underline{G}(24.54 \%)$ and C16192C $(14.10 \%)$ \\
\hline & Mother-Bl (M512) & $\mathrm{A} 3243 \mathrm{G}(13.13 \%), \mathrm{A} 5539 \underline{\mathrm{A}}(23.13 \%)$ and C16192C $(22.78 \%)$ \\
\hline & Child-Bl (M512-C) & $\mathrm{A} 3243 \underline{\overline{\mathrm{A}}}(41.01 \%), \mathrm{A} 5539 \underline{\underline{\mathrm{G}}}(31.26 \%)$ and C16192C $(17.30 \%)$ \\
\hline \multirow[t]{4}{*}{7} & Mother-Bu (1098) & $\mathrm{T} 16093 \mathrm{C}(11.53 \%)$ \\
\hline & Child-Bu (1100) & $\mathrm{T} 16093 \mathrm{~T}(3.45 \%)$ \\
\hline & Mother-Bl (M520) & $\mathrm{T} 16093 \bar{C}(9.12 \%)$ \\
\hline & Child-Bl (M520-C) & ND \\
\hline \multirow[t]{4}{*}{8} & Mother-Bu (1267) & $\mathrm{T} 2352 \mathrm{~T}(48.11 \%)$ \\
\hline & Child-Bu (1160) & $\mathrm{T} 2352 \mathrm{~T}(26.81 \%)$ \\
\hline & Mother-Bl (SC16) & T2352T $(47.93 \%)$ \\
\hline & Child-Bl (SC16-C) & T2352T (26.84\%) \\
\hline \multirow[t]{4}{*}{9} & Mother-Bu (839) & C11635T (8.34\%) \\
\hline & Child-Bu (1189) & C11635T (17.93\%) \\
\hline & Mother-Bl (M494) & $\mathrm{C} 11635 \mathrm{~T}(7.23 \%)$ \\
\hline & Child-Bl (M494-C) & C11635T (19.88\%) \\
\hline \multirow[t]{4}{*}{10} & Mother-Bu (632) & G15047A (21.08\%) \\
\hline & Child-Bu (696) & G15047A (26.67\%) \\
\hline & Mother-Bl (M236) & G15047A (19.47\%) \\
\hline & Child-Bl (M236-C) & G15047A (28.22\%) \\
\hline \multirow[t]{4}{*}{11} & Mother-Bu (531) & C5107T (9.74\%) \\
\hline & Child-Bu (572) & C5107T (13.07\%) \\
\hline & Mother-Bl (M-188) & C5107T (8.19\%) \\
\hline & Child-Bl (M188-C) & C5107T (10.05\%) \\
\hline \multirow[t]{4}{*}{12} & Mother-Bu (616) & $\mathrm{T} 15262 \mathrm{C}(8.36 \%)$ \\
\hline & Child-Bu (643) & $\mathrm{T} 15262 \mathrm{C}(15.81 \%)$ \\
\hline & Mother-Bl (M252) & $\mathrm{T} 15262 \mathrm{C}(7.46 \%)$ \\
\hline & Child-Bl (M252-C) & T15262C (15.49\%) \\
\hline
\end{tabular}

Bu: buccal cell; Bl: blood. 
The 14 distinct sites of shared heteroplasmy spanned the mtgenome, with $71 \%$ (10 of 14 ) occurring in the coding region. Of the 14 sites, four occurred in transfer RNA (tRNA) and ribosomal RNA (rRNA) genes, four sites resulted in synonymous changes to protein sequence, and two sites resulted in non-synonymous changes (Table S2). This is consistent with previous findings regarding the selection (cleansing) of potentially deleterious variants from the heteroplasmic pool [32]. Interestingly, in the current study a large region void of heteroplasmic sites was observed from nps 6153-10872, including the latter portion of the cytochrome oxidase 1 gene, all of cytochrome oxidase 2 and 3, ATP synthase 6 and 8 , and NADH dehydrogenase 3, along with multiple tRNA genes. While potentially impactful, this finding is most likely due to sample size, as previous studies have found multiple sites of heteroplasmy throughout this region [28], albeit in a different population group (Han Chinese).

The findings above are consistent with a recent report on the analysis of mtgenomes from 194 mother-child pairs [28], where 30 of the 194 pairs (16\%) exhibited shared heteroplasmy, and where the major haplotype shifted to the other variant in four instances. The difference in rates of shared heteroplasmy (16\% v. 31\%) can be attributed to the different approaches employed. The read coverage for each nucleotide was low (approximately 650 reads) for the previous study, with a requirement of 40 reads of the minor variant and a reporting threshold for heteroplasmy set at $10 \%$. The current study had an average coverage rate of 24,335, with the same requirement of 40 reads for the minor variant, and a reporting threshold of $2 \%$. Of the 12 pairs in the current study with shared heteroplasmy, three exhibited heteroplasmy below $10 \%$ for all samples tested, and another six pairs had at least one sample with heteroplasmy below $10 \%$. If the low-coverage, high-threshold approach were applied to this data the rates of shared heteroplasmy would have dropped to $8-23 \%$, which encompasses the rate from the previous study. As expected when considering shared heteroplasmy, 75\% of the pairs in the current study (9 of 12 pairs) had heteroplasmy greater than $10 \%$ in one or more samples, with $25 \%$ of the pairs exhibiting heteroplasmy greater than $10 \%$ in all four tissue samples. In general, when levels of heteroplasmy are relatively high, it is expected that the heteroplasmy will be more often shared by maternal relatives. Most importantly, the ability to report heteroplasmic variants at a lower threshold when using a DCMPS approach clearly increases the likelihood of identifying sites of shared heteroplasmy, with this observation holding true for differentiating heteroplasmy.

\subsection{Differentiating Heteroplasmy}

A summary of the metadata associated with differentiating heteroplasmy for the 39 mother-child pairs can be found in Table S2, with comparisons to shared and random heteroplasmy in Table S3. A total of 17 pairs (44\%) exhibited differentiating heteroplasmy (summarized in Table 2), defined as one of the two family members having the same site of heteroplasmy in both buccal and blood samples, with the absence of the same site of heteroplasmy in the buccal and blood samples from the other family member. Potential SNP-based heteroplasmy at np 310 was not included in the analysis. A total of 21 distinct sites of differentiating heteroplasmy were identified in the 17 pairs, with a single site of heteroplasmy observed in 14 of the pairs. In two family units (Nos. 6 and 15, Table 2; Nos. 10 and 23 , Table S2), both the mother and child had a site of differentiating heteroplasmy. The location of these sites varied from the CR to both synonymous and non-synonymous changes to protein sequence, with three of the four sites located in the coding region. In a third family unit (No. 11, Table 2; No. 19, Table S2), the mother had a single site of differentiating heteroplasmy, while the child had two sites. All three sites were in the coding region; one non-synonymous change to the ATP synthase 6 gene, one change to the $16 \mathrm{~S}$ rRNA sequence, and one change to the tRNA ${ }^{\text {thr }}$ gene. Based on these findings, it is quite possible that multiple sites of differentiating heteroplasmy will be observed when comparing the mtgenome sequences from maternal relatives; $18 \%$ of the families ( 3 of 17) exhibited multiple sites of differentiating heteroplasmy. 
Table 2. Differentiating heteroplasmy for 17 of the 39 mother-child pairs; buccal cell (Bu) and blood (Bl) samples. Frequency of heteroplasmy at each np in percentage (\%), with the minor variant annotated as the letter after the np; i.e., T2746C is heteroplasmy at np 2746 , with $20.11 \%$ of the $\mathrm{C}$ variant. Coverage and read distribution (forward reads, \#For, compared to reverse reads, \#Rev) are provided for each np of differentiating heteroplasmy, along with the gene annotation and whether sites in protein coding genes result in a synonymous change $(\mathrm{Y})$ or not $(\mathrm{N})$. The gene annotations include: $\mathrm{CR}=$ control region, $12 \mathrm{~S} \& 16 \mathrm{~S}=12 \mathrm{~S} \& 16 \mathrm{~S}$ rRNAs, ATP6 = ATP synthase 6, ND = NADH dehydrogenase, $\mathrm{tRNA}^{\text {thr }}=$ tRNA for threonine, and CO = cytochrome oxidase. Metadata for samples without the heteroplasmy are provided to illustrate that read percentages are clearly below reporting threshold and that coverage was adequate for this assessment.

\begin{tabular}{|c|c|c|c|c|c|c|c|c|c|c|}
\hline $\begin{array}{l}\text { Mother-Child } \\
\text { Pair } \\
\end{array}$ & $\begin{array}{l}\text { Nucleotide } \\
\text { Position }\end{array}$ & Sample Number & $\begin{array}{l}\text { Major } \\
\text { Allele }\end{array}$ & $\begin{array}{c}\text { Coverage } \\
\text { (\#For:\#Rev Reads) }\end{array}$ & $\begin{array}{c}\text { Major } \\
\text { Frequency (\%) }\end{array}$ & $\begin{array}{l}\text { Minor } \\
\text { Allele }\end{array}$ & $\begin{array}{c}\text { Coverage } \\
\text { (\#For:\#Rev Reads) }\end{array}$ & $\begin{array}{c}\text { Minor } \\
\text { Frequency (\%) }\end{array}$ & $\begin{array}{c}\text { Gene } \\
\text { Annotation }\end{array}$ & $\begin{array}{c}\text { Synonymous } \\
(\mathrm{Y} \text { or } \mathrm{N})\end{array}$ \\
\hline \multirow[t]{4}{*}{1} & T2746C & Mother - Bu (693) & $\mathrm{T}$ & $2920: 6014$ & 79.67 & $\mathrm{C}$ & $655: 1600$ & 20.11 & $16 \mathrm{~S}$ & \\
\hline & & Child - Bu (677) & $\mathrm{T}$ & 4838:14038 & 99.64 & C & $1: 9$ & 0.053 & & \\
\hline & & Mother - Bl (M207) & $\mathrm{T}$ & 14187:14328 & 80.3 & $\mathrm{C}$ & $3440: 3528$ & 19.62 & $16 \mathrm{~S}$ & \\
\hline & & Child - Bl (M207-C) & $\mathrm{T}$ & 24044:24176 & 99.88 & C & 6:12 & 0.037 & & \\
\hline \multirow[t]{4}{*}{2} & C16320T & Mother - Bu (406) & $\mathrm{C}$ & $4918: 3843$ & 72.33 & $\mathrm{~T}$ & 1866:1474 & 27.57 & $\mathrm{CR}$ & \\
\hline & & Child - Bu (444) & C & 17616:13273 & 99.92 & $\mathrm{~T}$ & $9: 7$ & 0.052 & & \\
\hline & & Mother - Bl (M137) & C & 5412:4619 & 94.9 & $\mathrm{~T}$ & $288: 248$ & 5.07 & $\mathrm{CR}$ & \\
\hline & & Child - Bl (M137-C) & C & $4232: 3670$ & 99.92 & $\mathrm{~T}$ & $2: 1$ & 0.038 & & \\
\hline \multirow[t]{3}{*}{3} & T9179C & Mother - Bu (1134) & $\mathrm{T}$ & 3063:5076 & 85.02 & C & $538: 892$ & 14.93 & ATP6 & $\mathrm{N}$ (Val to Ala) \\
\hline & & Mother - Bl (M502G) & $\mathrm{T}$ & 16583:20269 & 87.14 & C & 2468:2934 & 12.77 & ATP6 & $\mathrm{N}$ (Val to Ala) \\
\hline & & Child - Bl (M501) & $\mathrm{T}$ & 38769:44060 & 99.81 & C & $32: 24$ & 0.067 & & \\
\hline \multirow[t]{4}{*}{4} & G14040A & Mother - Bu (659) & G & 5770:4227 & 92.01 & A & $474: 381$ & 7.86 & ND5 & $\mathrm{Y}(\mathrm{Gln})$ \\
\hline & & Child - Bu (722) & G & 20789:16141 & 99.86 & A & $8: 12$ & 0.054 & & \\
\hline & & Mother - Bl (M242) & G & 13200:12992 & 94.07 & A & $831: 811$ & 5.89 & ND5 & $\mathrm{Y}(\mathrm{Gln})$ \\
\hline & & Child - Bl (M242-C) & G & $10355: 10087$ & 99.88 & A & $5: 5$ & 0.049 & & \\
\hline \multirow[t]{4}{*}{5} & T14461C & Mother - Bu (411) & $\mathrm{T}$ & 7078:7720 & 97.04 & $\mathrm{C}$ & $205: 233$ & 2.87 & ND6 & $\mathrm{Y}(\mathrm{Thr})$ \\
\hline & & Child - Bu (401) & $\mathrm{T}$ & 16084:15992 & 99.78 & $\mathrm{C}$ & $35: 18$ & 0.165 & & \\
\hline & & Mother - Bl (M132) & $\mathrm{T}$ & $8475: 8875$ & 97.54 & $\mathrm{C}$ & $193: 237$ & 2.41 & ND6 & $\mathrm{Y}(\mathrm{Thr})$ \\
\hline & & Child - Bl (M132-C) & $\mathrm{T}$ & $5854: 6622$ & 99.92 & C & $8: 1$ & 0.072 & & \\
\hline \multirow{7}{*}{6} & & Child - Bu (737) & G & 8943:15813 & 99.8 & A & $8: 3$ & 0.044 & & \\
\hline & & Mother - Bl (M203) & G & $4728: 5871$ & 97.1 & A & 133:167 & 2.74 & ND4 & $\mathrm{N}$ (Ala to Thr) \\
\hline & & Child - Bl (M203-C) & G & $14625: 18730$ & 99.88 & A & 6:5 & 0.033 & & \\
\hline & T12375C & Mother - Bu (711) & $\mathrm{T}$ & 1713:1597 & 99.67 & $\mathrm{C}$ & $1: 9$ & 0.301 & & \\
\hline & & Child - Bu (737) & $\mathrm{T}$ & 6368:6238 & 72.03 & C & 2770:2099 & 27.82 & ND5 & $\mathrm{Y}(\mathrm{Thr})$ \\
\hline & & Mother - Bl (M203) & $\mathrm{T}$ & 4588:4190 & 99.66 & C & 13:12 & 0.284 & & \\
\hline & & Child - Bl (M203-C) & $\mathrm{T}$ & 10455:10132 & 76 & C & $3481: 3008$ & 23.95 & ND5 & $\mathrm{Y}(\mathrm{Thr})$ \\
\hline \multirow[t]{4}{*}{7} & A13790G & Mother - Bu (729) & A & $2539: 943$ & 99.63 & G & $1: 1$ & 0.057 & & \\
\hline & & Child - Bu (684) & A & 5501:2427 & 88.46 & G & 650:356 & 11.22 & ND5 & $\mathrm{N}$ (Tyr to Cys) \\
\hline & & Mother - Bl (M213) & A & 10487:7516 & 99.46 & G & $4: 25$ & 0.160 & & \\
\hline & & Child - Bl (M213-C) & A & $5900: 4359$ & 88.44 & G & $705: 583$ & 11.1 & ND5 & $N$ (Tyr to Cys) \\
\hline
\end{tabular}


Table 2. Cont

\begin{tabular}{|c|c|c|c|c|c|c|c|c|c|c|}
\hline $\begin{array}{l}\text { Mother-Child } \\
\text { Pair }\end{array}$ & $\begin{array}{c}\text { Nucleotide } \\
\text { Position }\end{array}$ & Sample Number & $\begin{array}{l}\text { Major } \\
\text { Allele }\end{array}$ & $\begin{array}{c}\text { Coverage } \\
\text { (\#For:\#Rev Reads) }\end{array}$ & $\begin{array}{c}\text { Major } \\
\text { Frequency (\%) }\end{array}$ & $\begin{array}{l}\text { Minor } \\
\text { Allele }\end{array}$ & $\begin{array}{c}\text { Coverage } \\
\text { (\#For:\#Rev Reads) }\end{array}$ & $\begin{array}{c}\text { Minor } \\
\text { Frequency (\%) }\end{array}$ & $\begin{array}{c}\text { Gene } \\
\text { Annotation }\end{array}$ & $\begin{array}{c}\text { Synonymous } \\
\text { (Y or N) }\end{array}$ \\
\hline \multirow[t]{4}{*}{8} & A200A & Mother - Bu (1098) & G & $1350: 3677$ & 96.58 & $\mathrm{~A}$ & $31: 139$ & 3.26 & $\mathrm{CR}$ & \\
\hline & & Child - Bu (1100) & G & $1148: 3998$ & 98.79 & A & $5: 54$ & 1.13 & & \\
\hline & & Mother - Bl (M520) & G & 821:1294 & 97.6 & A & $17: 32$ & 2.26 & $C R$ & \\
\hline & & Child - Bl (M520-C) & G & 5713:9174 & 99.59 & A & 14:41 & 0.368 & & \\
\hline \multirow[t]{4}{*}{9} & A4191T & Mother - Bu (1122) & A & $8781: 10930$ & 99.36 & $\mathrm{~T}$ & $2: 27$ & 0.146 & & \\
\hline & & Child - Bu (1119) & A & $4452: 5729$ & 95.5 & $\mathrm{~T}$ & $202: 243$ & 4.17 & ND1 & Y (Pro) \\
\hline & & Mother - Bl (M500) & A & $5699: 6469$ & 99.37 & $\mathrm{~T}$ & $3: 25$ & 0.229 & & \\
\hline & & Child - Bl (M500-C) & A & $12277: 14284$ & 94.96 & $\mathrm{~T}$ & 612:695 & 4.67 & ND1 & Y (Pro) \\
\hline \multirow[t]{3}{*}{10} & A16170G & Mother - Bu (1267) & A & 17593:21027 & 94.49 & G & 1060:1174 & 5.46 & $\mathrm{CR}$ & \\
\hline & & Mother - Bl (SC16) & A & $8155: 10691$ & 96.19 & G & $332: 413$ & 3.8 & $\mathrm{CR}$ & \\
\hline & & Child - Bl (SC16-C) & A & 10154:13352 & 99.97 & G & $1: 2$ & 0.013 & & \\
\hline \multirow[t]{11}{*}{11} & G9196A & Mother - Bu (839) & G & 6061:10535 & 97.36 & A & $172: 265$ & 2.56 & ATP6 & $\mathrm{N}$ (Asp to \\
\hline & & Child - Bu (1189) & G & $4644: 7284$ & 99.81 & A & $0: 6$ & 0.050 & & \\
\hline & & Mother - Bl (M494) & G & 14294:16248 & 97.83 & A & $306: 362$ & 2.13 & ATP6 & $\mathrm{N}$ (Asp to \\
\hline & & Child - Bl (M494-C) & G & 10236:11242 & 99.95 & A & $0: 3$ & 0.014 & & \\
\hline & T3183C & Mother - Bu (839) & $\mathrm{T}$ & $12953: 24373$ & 99.67 & $\mathrm{C}$ & $26: 53$ & 0.211 & & \\
\hline & & Child - Bu (1189) & $\mathrm{T}$ & $12210: 26317$ & 96.49 & $\mathrm{C}$ & 412:937 & 3.37 & $16 \mathrm{~S}$ & \\
\hline & & Mother - Bl (M494) & $\mathrm{T}$ & $36453: 46743$ & 99.85 & $\mathrm{C}$ & $40: 63$ & 0.124 & & \\
\hline & A15948G & Mother - Bu (839) & A & $15680: 15099$ & 99.87 & G & $13: 13$ & 0.084 & & \\
\hline & & Child - Bu (1189) & A & 21533:19721 & 95.35 & G & 1039:902 & 4.48 & tRNA ${ }^{\text {thr }}$ & \\
\hline & & Mother - Bl (M494) & A & $24430: 24443$ & 99.95 & G & $7: 7$ & 0.029 & & \\
\hline & & Child - Bl (M494-C) & A & 30887:30673 & 96.64 & G & 1074:1041 & 3.32 & tRNA $^{\text {thr }}$ & \\
\hline \multirow[t]{4}{*}{12} & C11288T & Mother - Bu (740) & $\mathrm{C}$ & 18404:14646 & 99.97 & $\mathrm{~T}$ & $2: 1$ & 0.009 & & \\
\hline & & Child - Bu (718) & C & 68908:55901 & 95.69 & $\mathrm{~T}$ & $3140: 2418$ & 4.26 & ND4 & Y (Leu) \\
\hline & & Mother - Bl (M211) & $\mathrm{C}$ & 38204:36874 & 99.95 & $\mathrm{~T}$ & $8: 17$ & 0.033 & & \\
\hline & & Child - Bl (M211-C) & C & 46511:43582 & 96.58 & $\mathrm{~T}$ & $1651: 1523$ & 3.4 & ND4 & $\mathrm{Y}(\mathrm{Leu})$ \\
\hline \multirow{4}{*}{13} & T596C & Mother - Bu (739) & $\mathrm{T}$ & $3088: 856$ & 84.7 & $\mathrm{C}$ & $552: 155$ & 15.18 & tRNA ${ }^{\text {phe }}$ & \\
\hline & & Child - Bu (725) & $\mathrm{T}$ & 9324:2728 & 99.37 & $\mathrm{C}$ & 3:13 & 0.132 & & \\
\hline & & Mother - Bl (M200) & $\mathrm{T}$ & $1745: 1125$ & 95.15 & $\mathrm{C}$ & $93: 52$ & 4.8 & tRNA ${ }^{\text {phe }}$ & \\
\hline & & Child - Bl (M200-C) & $\mathrm{T}$ & $5520: 3270$ & 99.82 & C & $8: 4$ & 0.136 & & \\
\hline \multirow[t]{4}{*}{14} & A926G & Mother - Bu (605) & A & $7528: 4119$ & 96.48 & G & $275: 147$ & 3.49 & $12 \mathrm{~S}$ & \\
\hline & & Child - Bu (619) & A & 23698:18664 & 99.95 & G & $7: 5$ & 0.028 & & \\
\hline & & Mother - Bl (M240) & A & $3882: 3469$ & 96.29 & G & 149:131 & 3.66 & $12 \mathrm{~S}$ & \\
\hline & & Child - Bl (M240-C) & A & 4476:4483 & 99.92 & G & $2: 2$ & 0.043 & & \\
\hline
\end{tabular}


Table 2. Cont

\begin{tabular}{|c|c|c|c|c|c|c|c|c|c|c|}
\hline $\begin{array}{l}\text { Mother-Child } \\
\text { Pair }\end{array}$ & $\begin{array}{c}\text { Nucleotide } \\
\text { Position }\end{array}$ & Sample Number & $\begin{array}{l}\text { Major } \\
\text { Allele }\end{array}$ & $\begin{array}{c}\text { Coverage } \\
\text { (\#For:\#Rev Reads) }\end{array}$ & $\begin{array}{c}\text { Major } \\
\text { Frequency (\%) }\end{array}$ & $\begin{array}{l}\text { Minor } \\
\text { Allele }\end{array}$ & $\begin{array}{c}\text { Coverage } \\
\text { (\#For:\#Rev Reads) }\end{array}$ & $\begin{array}{c}\text { Minor } \\
\text { Frequency (\%) }\end{array}$ & $\begin{array}{c}\text { Gene } \\
\text { Annotation }\end{array}$ & $\begin{array}{l}\text { Synonymous } \\
\text { (Y or N) }\end{array}$ \\
\hline \multirow[t]{8}{*}{15} & A14573G & Mother - Bu (632) & A & $3406: 2340$ & 70.79 & G & 1390:966 & 29.02 & ND6 & $\mathrm{N}$ (Val to Ala) \\
\hline & & Child - Bu (696) & A & $5484: 4707$ & 99.73 & G & $1: 4$ & 0.049 & & \\
\hline & & Mother - Bl (M236) & A & $7546: 6525$ & 77.51 & G & 2240:1839 & 22.47 & ND6 & $\mathrm{N}$ (Val to Ala) \\
\hline & & Child - Bl (M236-C) & A & $8151: 7438$ & 99.95 & G & $3: 1$ & 0.026 & & \\
\hline & A214G & Mother - Bu (632) & A & $886: 2300$ & 99.75 & G & $3: 4$ & 0.219 & & \\
\hline & & Child - Bu (696) & A & $1739: 2434$ & 91.43 & G & $156: 230$ & 8.45 & $\mathrm{CR}$ & \\
\hline & & Mother - Bl (M236) & A & $3777: 4526$ & 99.99 & G & $0: 1$ & 0.012 & & \\
\hline & & Child - Bl (M236-C) & A & $3426: 4146$ & 96.87 & G & 119:124 & 3.1 & $\mathrm{CR}$ & \\
\hline \multirow[t]{3}{*}{16} & A16240G & Mother - Bu (531) & A & 1424:1744 & 99.75 & G & $3: 2$ & 0.157 & & \\
\hline & & Mother - Bl (M-188) & A & $16073: 16853$ & 99.88 & G & $4: 9$ & 0.039 & & \\
\hline & & Child - Bl (M188-C) & A & 13732:14444 & 94.28 & G & $823: 855$ & 5.61 & $\mathrm{CR}$ & \\
\hline \multirow[t]{4}{*}{17} & A9983G & Mother - Bu (616) & A & 2944:7014 & 99.83 & G & $5: 12$ & 0.170 & & \\
\hline & & Child - Bu (643) & A & 11623:20991 & 97.33 & G & 314:547 & 2.56 & $\mathrm{CO} 3$ & $Y(\operatorname{Trp})$ \\
\hline & & Mother - Bl (M252) & A & 11354:14962 & 99.83 & G & $18: 22$ & 0.152 & & \\
\hline & & Child - Bl (M252-C) & A & $17123: 22272$ & 97.91 & G & $346: 468$ & 2.02 & $\mathrm{CO} 3$ & $Y(\operatorname{Trp})$ \\
\hline
\end{tabular}


No significant correlation to the origin of the differentiating heteroplasmy was observed in our data, as nine of the 21 sites (43\%) were limited to the child, while the remaining 12 sites were restricted to the mother. In addition, the rates of differentiating heteroplasmy were not well correlated to tissue type, consistent with how it was delineated in the current study; i.e., that the heteroplasmy had to be observed in both buccal and blood cells. Consistent with expectations, 91\% of the sites (19 of 21) associated with buccal samples had higher rates of heteroplasmy when compared to blood samples. However, an assessment of the rates for each site revealed that most sites had a narrow range of variant frequencies between the two tissue types. The vast majority of sites $(81 \%, 17$ of 21$)$ exhibited less than a twofold difference in the rate values. Exceptions included a family unit (No. 2, Table 2; No. 4, Table S2) with $5.07 \%$ heteroplasmy at np 16320 of the CR in the blood of the mother, with $27.57 \%$ heteroplasmy in her buccal sample; an approximately fivefold difference in rates. The remaining three exceptions ranged from a two to threefold change in rates.

Compared to shared heteroplasmy, the rate of differentiating heteroplasmy was more often observed in the range of $2-10 \%$ (Table S3). Approximately $67 \%$ of sites (14 of 21) exhibited differentiating heteroplasmy below $10 \%$ for each of the tissue types, while the frequency of heteroplasmy at only 5 of 21 sites (24\%) was greater than $10 \%$ for both tissues. In contrast, only $21 \%$ of sites ( 3 of 14) with shared heteroplasmy had frequencies below $10 \%$, while $36 \%$ (5 of 14 ) had greater than $10 \%$ heteroplasmy for all tissues tested. The average frequency of shared heteroplasmy across all samples was $15.6 \%$, while the average for differentiating heteroplasmy was $8.6 \%$ (significantly lower, $p=9.2 \times 10^{-4}$ ), emphasizing the importance of read depth and reporting thresholds when attempting to identify sites of differentiating heteroplasmy. Coverage for each position of both shared and differentiating heteroplasmy was greater than 2000, and typically greater than 10,000 reads allowing for the application of a DCMPS approach.

\subsection{Random Heteroplasmy}

A summary of the metadata associated with random heteroplasmy for 29 of the 39 mother-child pairs can be found in Table S2, with comparisons to shared and differentiating heteroplasmy in Table S3. Random heteroplasmy was defined as sites not replicated in the second tissue type of the same individual, and not observed in the other family member in a mother-child pair. These sites are presumed to originate from de novo mutations or low-level sites of heteroplasmy not detected in other tissues or the second individual in a pair. Potential SNP-based heteroplasmy at np 310 was not included in the analysis. A total of 20 of the 39 pairs (52\%) exhibited random sites of heteroplasmy across the mtgenome, with an average of 0.77 heteroplasmies per pair, and 0.39 per individual. Of the 30 sites of random heteroplasmy, 24 sites were observed once, and three sites were observed twice; nps 215, 16093 and 16189. Fourteen of the 30 sites were located in the CR, while the remaining 16 (53\%) were located in the coding region, once again highlighting the value of sequencing the entire mtgenome.

The frequency of the minor variant for random sites of heteroplasmy was significantly lower than the sites of shared $\left(p=2.2 \times 10^{-5}\right)$ and differentiating heteroplasmy $\left(p=5.0 \times 10^{-4}\right)$ and differentiating heteroplasmy was significantly lower than shared $\left(p=9.2 \times 10^{-4}\right)$. The average frequency was $3.8 \%$, compared to $8.6 \%$ for differentiating heteroplasmy and $15.6 \%$ for shared heteroplasmy. A single site of random heteroplasmy (np 16093) had a frequency greater than $10 \%$, while 13 of the 30 sites were between $3-10 \%$, and 16 sites had a frequency between $2-3 \%$. This is an expected outcome, as random heteroplasmy typically has not accumulated to a high level. Interestingly, of the 30 sites of random heteroplasmy, seven sites (23\%) were observed in mothers, while $77 \%$ were found in children. These values are trending towards the younger of the two individuals in the pair but are not significantly different $(p=0.33$ ) and reflect the inconsistent reporting of whether heteroplasmy is strongly correlated to age. In addition, an important consideration is the tissue type being tested. In the current study, 24 of the 30 sites of random heteroplasmy were observed in buccal samples, consistent with previous reports of elevated levels of heteroplasmy in buccal cells. 


\subsection{Coverage and Error Rates}

Using the DCMPS approach for the current study, average coverage across the mtgenome was 24,335 reads per nucleotide position. The depth of coverage was $>2000$ reads for $98.7 \%$ of the nucleotide positions, allowing for the application of a $2 \%$ threshold given the requirement of 40 reads for a minor variant to be reported. Approximately one third of the samples tested (52/156) had a depth of coverage exceeding 2000 for all 16,569 nucleotide positions, another third had <100 nucleotide positions with coverage $<2000$, and the final third varied in the number of positions under 2000 reads. The majority of observations of coverage $<2000$ occurred between nps 301-530 and 3567-3572, a relatively narrow range of the mtgenome, although approximately $35 \%$ of the positions were affected at some level. Regions that produced low coverage generally did so due to the challenges of producing quality sequence data through certain regions of the mtgenome and the nature of the alignment strategy of the GM HTS software. For example, motif driven alignment resulted in a reduction in coverage for regions of homopolymeric and repetitive sequence, as trimming reduced the read depth in the range of sequence being aligned. Nonetheless, all mother-child pairs with differentiating heteroplasmy were manually evaluated to ensure that sites observed to have no heteroplasmy at corresponding nucleotide positions were not removed due to coverage-related filtering. In each case, sufficient read coverage to apply a $2 \%$ threshold was confirmed, and across each tissue type (Table 2).

To confirm that heteroplasmy was due to true signal above noise associated with amplification, library preparation, and sequencing on the MiSeq, the substitution-based error rate at each nucleotide position across the mtgenome was calculated for all nucleotides (A, C, G, and T). Greater than 60 billion total base calls were used for the analysis, taken from the quality-filtered dataset, as quality trimming has been shown to improve error rates [45]. Error profiles for MPS data are not well understood [40], and the available methods for error rate estimation are limited [46]. Therefore, our approach to calculating assumed substitution-based error was conservative, including all base calls with frequencies less than or equal to $50 \%$ in the calculation. Given that MiSeq calls have been shown to be concordant with traditional Sanger sequencing [31,47], the 50\% cut-off represents a worse-case scenario and is marginally inflated due to the inclusion of known heteroplasmic variants.

The consensus statistic reports generated by GM HTS were used to calculate error rates based on the number of times each nucleotide was called in relation to total coverage, and then filtered to include only calls with $<50 \%$ frequency. Assumed error was then evaluated in two ways, looking at an average error rate and a rate based on each nucleotide position. For the average error, the number of calls for each nucleotide (A, C, G, and T) was summed across all samples for all 16,569 nucleotide positions and divided by the sum of coverage across all samples for all 16,569 positions. The observed error for each nucleotide position was calculated by summing the number of calls for each nucleotide across all samples at each position (1-16,569) and dividing the sum of the coverage across all samples at each nucleotide position. This generated 16,569 rates for A, C, G, and T (Figures 1-4). The average assumed substitution-based error rate for each nucleotide was well below our threshold of $2 \%$ (Table 3), indicating that heteroplasmic positions reported at $2 \%$ are well above the noise of the system. The average rates indicate the system as a whole has low error, which has been shown by others $[40,48,49]$, but this assessment does not provide information as to whether hotspots of error exist at specific locations across the mtgenome.

Table 3. Substitution-based error rates for A, C, G, and T base calls. Error Rates represent the total numbers of calls made in error at all nucleotide positions (16,569 positions) divided by the total number of sequencing base calls.

\begin{tabular}{ccccc}
\hline & rCRS $>$ A & rCRS $>$ C & rCRS $>$ G & rCRS $>$ T \\
\hline Error Rate & 0.0343 & 0.0565 & 0.0331 & 0.0304 \\
\hline \multicolumn{5}{c}{ rCRS: revised Cambridge Reference Sequence. }
\end{tabular}




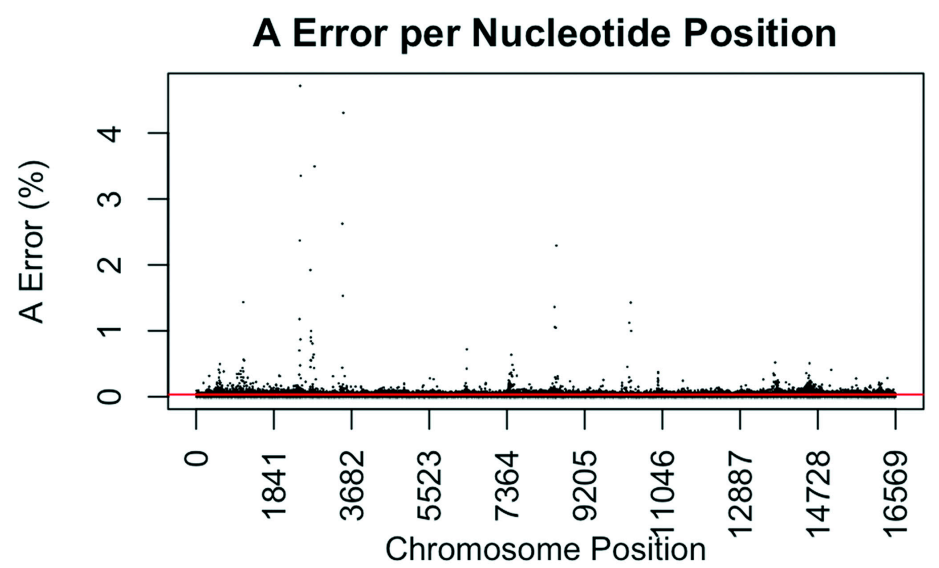

Figure 1. Substitution error rate for A (adenosine) nucleotides per nucleotide position across the mtgenome. The error rate was calculated by dividing the sum of all A calls assumed in error in all samples (all A calls observed at $<50 \%$ ) by the total number of calls (or reads) at that nucleotide position for all samples. The red line indicates the average A error $(0.0343 \%)$ for all nucleotide positions.

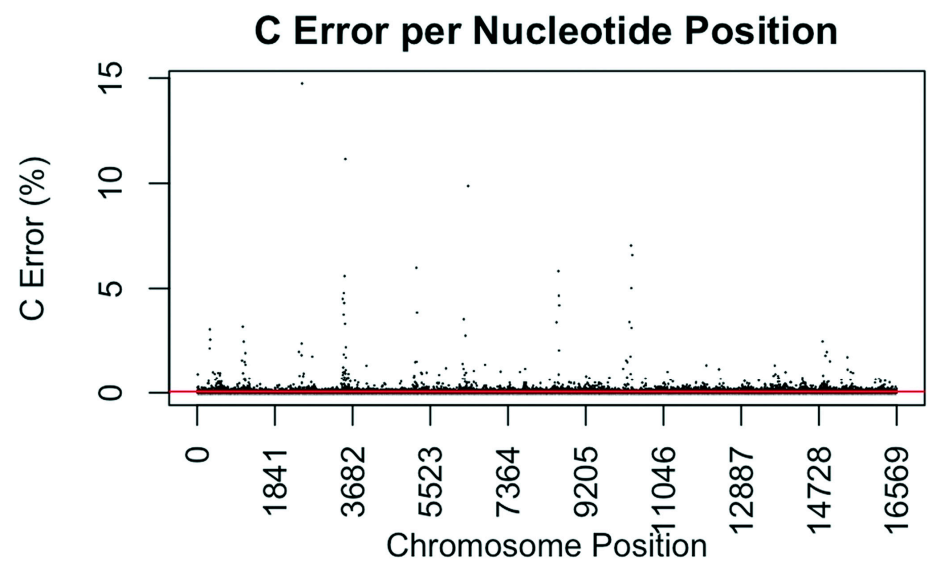

Figure 2. Substitution error rate for $C$ (cytidine) nucleotides per nucleotide position across the mtgenome. The error rate was calculated as described in Figure 1. The red line indicates the average $C$ error $(0.0565 \%)$ for all nucleotide positions.

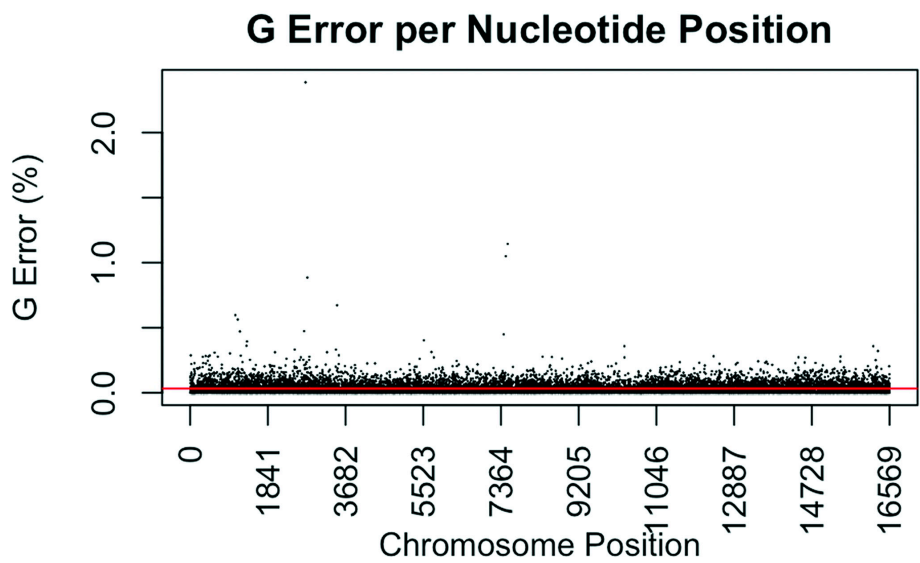

Figure 3. Substitution error rate for $\mathrm{G}$ (guanosine) nucleotides per nucleotide position across the mtDNA genome. The error rate was calculated as described in Figure 1. The red line indicates the average $\mathrm{G}$ error $(0.0331 \%)$ for all nucleotide positions. 


\section{T Error per Nucleotide Position}

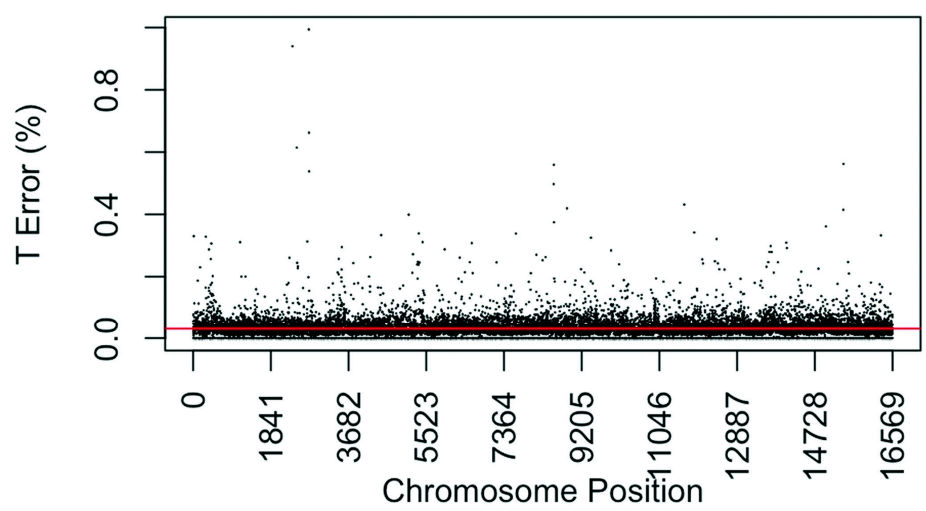

Figure 4. Substitution error rate for $\mathrm{T}$ (thymidine) nucleotides per nucleotide position across the mtgenome. The error rate was calculated as described in Figure 1. The red line indicates the average T error $(0.0304 \%)$ for all nucleotide positions.

Our evaluation of error for each nucleotide indicates that the assumed rate of error varies across the mtgenome and supports previous studies [50]. The highest rates of error for each nucleotide ( 25 rates for $A, G$, and $T$, and 35 for $C$; to include all $C$ rates $>2 \%$; 110 rates total) encompassed 105 positions with 99 of those positions falling within the coding region and nine positions within the $\mathrm{CR}$. The estimated $\mathrm{T}$ error did not surpass $1.05 \%$ at any position in the mtgenome, while G error surpassed $2 \%$ at one position (np 2734), A error surpassed $2 \%$ at seven positions, and C error had the greatest number of sites, 31 nucleotide positions, surpassing $2 \%$ (Table 4). Even though 39 nucleotide positions had error greater than our $2 \%$ threshold, no observations of heteroplasmy were reported at these positions. Manual inspection of multiple sequencing pile-ups indicate that these locations, while having a mixture of nucleotides, are not reported as valid heteroplasmic positions due to failing both the balance ratio as well as the quality score filtering parameters. The underlying reason for these spikes in error was determined to be motif driven, occurring in only one direction, and therefore not reported due to read imbalance filtering. These positions also had lower quality scores for the minor variant, causing the position to fail the quality score filter. Other studies have associated error with similar emission spectra of A/C or G/T fluorophores [39,40,51] and specific sequence patterns such as GGT [52,53] or AAA [48]. Our error assessment supports previous findings with over half of the top error sites being located adjacent to specific sequence motifs: $19 \%(21 / 110)$ adjacent to a sequence motif of at least three A nucleotides, 30\% (33/110) adjacent to at least three $\mathrm{C}$ nucleotides, and $6.3 \%$ $(7 / 110)$ associated with a motif of GGT. Our observations also support previous findings [54] that the most frequent type of error was $\mathrm{A}>\mathrm{C}$ or $\mathrm{C}>\mathrm{A}$ transversions (32\%). Other error sites consisted of $\mathrm{A}>\mathrm{T}$ or $\mathrm{T}>\mathrm{A}(26 \%)$, and $\mathrm{G}>\mathrm{T}$ or $\mathrm{T}>\mathrm{G}(16 \%)$ type errors. The error evaluation supports our reporting threshold of $2 \%$ when assessing minor sequence variants that represent heteroplasmies due to true signal above noise.

Table 4. Nucleotide positions and adjacent sequence for locations with the highest frequency error for each nucleotide type (A, C, G, and T). The adjacent sequence preceding and following the error site (noted as *) as given by the L-strand of the rCRS (NC_012920). The surrounding sequence is limited to motifs of three nucleotides unless the adjacent sequence is a homopolymeric stretch, in which case the entire complement is given.

\begin{tabular}{cccc}
\hline \multicolumn{3}{c}{ rCRS $>$ A error } & \\
\hline Adjacent Sequence & rCRS nt & np & Error \\
AAA ${ }^{*}$ TAC & $\mathrm{C}$ & 2785 & 0.669 \\
TCA AAG & $\mathrm{T}$ & 2445 & 0.722 \\
\hline
\end{tabular}


Table 4. Cont.

\begin{tabular}{|c|c|c|c|}
\hline $\mathrm{ATA}^{*} \mathrm{AAAA}$ & $\mathrm{T}$ & 6415 & 0.732 \\
\hline $\mathrm{AAA} * \mathrm{AGT}$ & $\mathrm{C}$ & 2756 & 0.836 \\
\hline $\mathrm{AGA}^{*} \mathrm{GAG}$ & $\mathrm{C}$ & 2718 & 0.875 \\
\hline $\mathrm{AAG}^{*} \mathrm{AAC}$ & $\mathrm{G}$ & 2471 & 0.900 \\
\hline $\mathrm{CAA}^{*} \mathrm{ACG}$ & G & 2716 & 0.920 \\
\hline $\mathrm{GAA}^{*} \mathrm{ACC}$ & G & 2724 & 1.013 \\
\hline $\mathrm{AAC}^{*} \mathrm{AAC}$ & $\mathrm{T}$ & 10,304 & 1.018 \\
\hline AAAAA*AAAAAA & $\mathrm{T}$ & 8496 & 1.079 \\
\hline AAC*AAAA & $\mathrm{C}$ & 8523 & 1.095 \\
\hline $\mathrm{CTA}^{*} \mathrm{AAA}$ & G & 10,260 & 1.130 \\
\hline $\mathrm{AAG}^{*} \mathrm{AAA}$ & G & 2449 & 1.223 \\
\hline $\mathrm{CCA}^{*} \mathrm{AAAAA}$ & $\mathrm{T}$ & 8490 & 1.395 \\
\hline CTA*AAA & $\mathrm{C}$ & 10,296 & 1.421 \\
\hline $\mathrm{AGT}^{*} \mathrm{AAA}$ & $\mathrm{T}$ & 1115 & 1.517 \\
\hline $\mathrm{CAC}^{*} \mathrm{AAA}$ & $\mathrm{C}$ & 3477 & 1.668 \\
\hline $\mathrm{TAA}^{*} \mathrm{ACA}$ & $\mathrm{C}$ & 2708 & 2.048 \\
\hline $\mathrm{AAC}{ }^{*} \mathrm{AAAA}$ & $\mathrm{G}$ & 8533 & 2.355 \\
\hline GGT $^{*}$ AAAAAAA & $\mathrm{T}$ & 2456 & 2.457 \\
\hline $\mathrm{CCA}^{*} \mathrm{AAAA}$ & $\mathrm{T}$ & 3464 & 2.784 \\
\hline $\mathrm{CGG}^{*} \mathrm{AAA}$ & $\mathrm{C}$ & 2479 & 3.371 \\
\hline AAAAA*TTC & $\mathrm{T}$ & 2806 & 3.634 \\
\hline $\mathrm{CCCC}^{*} \mathrm{AAAA}$ & $\mathrm{T}$ & 3488 & 4.629 \\
\hline AAAAAAAG ${ }^{*}$ AAAGG & $\mathrm{T}$ & 2465 & 4.787 \\
\hline & rCRS $>C$ error & & \\
\hline Adjacent Sequence & rCRS nt & $\mathrm{np}$ & Error \\
\hline $\mathrm{AAC}{ }^{*} \mathrm{CTA}$ & A & 1142 & 1.971 \\
\hline $\mathrm{TCT}^{*} \mathrm{CAC}$ & $\mathrm{T}$ & 3473 & 1.996 \\
\hline $\mathrm{CTC}^{*} \mathrm{CCA}$ & A & 14,914 & 2.010 \\
\hline $\mathrm{ATT}^{*} \mathrm{CCC}$ & A & 2412 & 2.051 \\
\hline $\mathrm{TAG}^{*} \mathrm{CCT}$ & G & 8573 & 2.157 \\
\hline $\mathrm{ATC}^{*} \mathrm{CCG}$ & A & 3523 & 2.214 \\
\hline $\mathrm{TCC}^{*} \mathrm{CCA}$ & A & 297 & 2.261 \\
\hline $\mathrm{AAC}{ }^{*} \mathrm{CGG}$ & $\mathrm{T}$ & 2475 & 2.363 \\
\hline $\mathrm{CCCC}^{*} \mathrm{CCCC}$ & $\mathrm{A}$ & 14,813 & 2.532 \\
\hline $\mathrm{TAA}^{*} \mathrm{CCT}$ & A & 1104 & 2.629 \\
\hline $\mathrm{CCCCССC}^{*} \mathrm{CCCCC}$ & $\mathrm{T}$ & 310 & 2.702 \\
\hline $\mathrm{TAC}^{*} \mathrm{CCT}$ & A & 6355 & 2.840 \\
\hline $\mathrm{TGA}^{*} \mathrm{CCC}$ & G & 10,290 & 3.220 \\
\hline $\mathrm{CAA}^{*} \mathrm{CCCCCCC}$ & A & 302 & 3.259 \\
\hline $\mathrm{GAT}^{*} \mathrm{CCCC}$ & $\mathrm{A}$ & 1082 & 3.365 \\
\hline $\mathrm{TCT}^{*} \mathrm{CCA}$ & $\mathrm{A}$ & 3505 & 3.387 \\
\hline $\mathrm{CAA}^{*} \mathrm{CCC}$ & A & 8512 & 3.419 \\
\hline $\mathrm{ATT}^{*} \mathrm{CCT}$ & A & 10,239 & 3.531 \\
\hline $\mathrm{CCC}^{*} \mathrm{CCC}$ & A & 6316 & 3.635 \\
\hline AAA ${ }^{*} \mathrm{CTC}$ & $\mathrm{A}$ & 3468 & 4.003 \\
\hline $\mathrm{TCC}^{*} \mathrm{CCC}$ & A & 5208 & 4.003 \\
\hline $\mathrm{CCT}^{*} \mathrm{CCC}$ & A & 8577 & 4.318 \\
\hline $\mathrm{AGA}^{*} \mathrm{CCCC}$ & G & 3483 & 4.614 \\
\hline $\mathrm{ACA}^{*} \mathrm{CCC}$ & $\mathrm{A}$ & 3447 & 4.753 \\
\hline $\mathrm{CAA}^{*} \mathrm{CCT}$ & $\mathrm{T}$ & 8567 & 4.799 \\
\hline $\mathrm{TTC}^{*} \mathrm{CCA}$ & $\mathrm{A}$ & 3475 & 4.954 \\
\hline $\mathrm{CCT}^{*} \mathrm{CCA}$ & A & 10,283 & 5.115 \\
\hline $\mathrm{AAA}^{*} \mathrm{CCC}$ & $\mathrm{A}$ & 3492 & 5.852 \\
\hline $\mathrm{ATT}^{*} \mathrm{CCCCC}$ & G & 8557 & 5.990 \\
\hline $\mathrm{AAC}{ }^{*} \mathrm{CCC}$ & $\mathrm{A}$ & 5192 & 6.157 \\
\hline $\mathrm{CTA}^{*} \mathrm{CCT}$ & A & 10,306 & 6.723 \\
\hline TTTT*CCCC & A & 10,277 & 7.210 \\
\hline $\mathrm{AAA}^{*} \mathrm{CCCCC}$ & A & 6419 & 10.035 \\
\hline $\mathrm{ATC}^{*} \mathrm{CCC}$ & A & 3511 & 11.371 \\
\hline $\mathrm{CTT}^{*} \mathrm{CCCC}$ & A & 2487 & 14.821 \\
\hline
\end{tabular}


Table 4. Cont.

\begin{tabular}{|c|c|c|c|}
\hline \multicolumn{4}{|c|}{ rCRS $>$ G error } \\
\hline Adjacent Sequence & rCRS nt & $\mathrm{np}$ & Error \\
\hline $\mathrm{CAC}^{*} \mathrm{CCC}$ & $\mathrm{T}$ & 466 & 0.301 \\
\hline $\mathrm{CAG}^{*} \mathrm{GCC}$ & $\mathrm{A}$ & 3243 & 0.301 \\
\hline AAC*GGC & $\mathrm{T}$ & 5717 & 0.311 \\
\hline $\mathrm{GAG}^{*} \mathrm{GTT}$ & $\mathrm{T}$ & 944 & 0.320 \\
\hline $\mathrm{GGGG}^{*} \mathrm{AGC}$ & A & 16,037 & 0.325 \\
\hline $\mathrm{AAA}^{*} \mathrm{CCCCC}$ & A & 16,183 & 0.326 \\
\hline $\mathrm{CCC}^{*} \mathrm{CCC}$ & A & 16,293 & 0.328 \\
\hline CAG*TTA & $\mathrm{T}$ & 578 & 0.329 \\
\hline $\mathrm{TGG}^{*} \mathrm{GAT}$ & $\mathrm{T}$ & 2010 & 0.329 \\
\hline $\mathrm{AAC}{ }^{*} \mathrm{CGG}$ & $\mathrm{T}$ & 2475 & 0.337 \\
\hline $\mathrm{CGC}^{*} \mathrm{GAC}$ & $\mathrm{T}$ & 3456 & 0.347 \\
\hline $\mathrm{TTA}^{*} \mathrm{CCC}$ & $\mathrm{C}$ & 10,287 & 0.358 \\
\hline AGG $^{*}$ GTA & $\mathrm{T}$ & 1335 & 0.376 \\
\hline $\mathrm{AAG}^{*} \mathrm{GCC}$ & A & 5539 & 0.382 \\
\hline $\mathrm{AGG}^{*} \mathrm{GGC}$ & $\mathrm{T}$ & 1349 & 0.406 \\
\hline CCG $^{*}$ ATA & $\mathrm{T}$ & 7429 & 0.444 \\
\hline $\mathrm{CGG}^{*} \mathrm{GCT}$ & $\mathrm{T}$ & 1180 & 0.487 \\
\hline GGG*ATA & $\mathrm{C}$ & 2703 & 0.501 \\
\hline $\mathrm{AAC}{ }^{*} \mathrm{GCT}$ & $\mathrm{T}$ & 1129 & 0.577 \\
\hline AAC*GGG & $\mathrm{T}$ & 1071 & 0.628 \\
\hline $\mathrm{AAG}^{*} \mathrm{GCC}$ & $\mathrm{A}$ & 3482 & 0.672 \\
\hline $\mathrm{AGG}^{*} \mathrm{CCT}$ & $\mathrm{T}$ & 2778 & 0.950 \\
\hline TGG*TTC & $\mathrm{T}$ & 7480 & 1.069 \\
\hline AGG*TAT & $\mathrm{T}$ & 7522 & 1.183 \\
\hline $\mathrm{TGG}^{*} \mathrm{GCT}$ & $\mathrm{A}$ & 2734 & 2.458 \\
\hline \multicolumn{4}{|c|}{ rCRS $>\mathrm{T}$ error } \\
\hline Adjacent Sequence & rCRS nt & $\mathrm{np}$ & Error \\
\hline $\mathrm{ATC}^{*} \mathrm{CCC}$ & A & 16 & 0.345 \\
\hline $\mathrm{CAA}^{*} \mathrm{CCCCCСC}$ & A & 302 & 0.343 \\
\hline GTC*CCCCCC & A & 432 & 0.322 \\
\hline ACA*TTA & G & 1113 & 0.320 \\
\hline $\mathrm{GAT}^{*} \mathrm{AAAA}$ & $\mathrm{T}$ & 2352 & 0.834 \\
\hline AAG*TTA & G & 2454 & 0.630 \\
\hline $\mathrm{TTT}^{*} \mathrm{ATT}$ & A & 2740 & 1.058 \\
\hline TTT*TTA & A & 2745 & 0.679 \\
\hline ATT*ATG & $\mathrm{A}$ & 2748 & 0.570 \\
\hline $\mathrm{TAT}^{*} \mathrm{CCC}$ & A & 4455 & 0.347 \\
\hline $\mathrm{CTA}^{*} \mathrm{TAC}$ & $\mathrm{C}$ & 5107 & 0.360 \\
\hline $\mathrm{TCT}^{*} \mathrm{CCT}$ & A & 5347 & 0.348 \\
\hline $\mathrm{ATC}^{*} \mathrm{CCT}$ & $\mathrm{A}$ & 7649 & 0.346 \\
\hline $\mathrm{TCT}^{*} \mathrm{TTC}$ & G & 8541 & 0.509 \\
\hline TCG*TTC & $\mathrm{C}$ & 8546 & 0.579 \\
\hline TTC*TTC & A & 8550 & 0.382 \\
\hline $\mathrm{AGC}^{*} \mathrm{GGC}$ & $\mathrm{G}$ & 8856 & 0.410 \\
\hline $\mathrm{ACC}^{*} \mathrm{CCT}$ & A & 9425 & 0.333 \\
\hline $\mathrm{CAG}^{*} \mathrm{CAC}$ & $\mathrm{C}$ & 11,635 & 0.377 \\
\hline $\mathrm{CCCCCC}^{*} \mathrm{CTA}$ & A & 11,873 & 0.354 \\
\hline $\mathrm{ACC}^{*} \mathrm{CCC}$ & A & 12,400 & 0.331 \\
\hline $\mathrm{GCT}^{*} \mathrm{CCT}$ & A & 14,988 & 0.370 \\
\hline $\mathrm{ATC}^{*} \mathrm{CCT}$ & A & 15,401 & 0.426 \\
\hline $\mathrm{TCC}^{*} \mathrm{CCC}$ & A & 15,408 & 0.579 \\
\hline $\mathrm{CCC}^{*} \mathrm{CCC}$ & A & 16,293 & 0.341 \\
\hline
\end{tabular}

\section{Conclusions}

Based on the findings of the current study, the ability to differentiate maternal relatives when conducting forensic mtDNA analysis is clearly possible on a routine basis when using a 
DCMPS approach. While it is certainly ideal to target the entire mtgenome, as the majority of the differentiating heteroplasmy was observed in the coding region (76\%), analysis of the CR may allow for the differentiation of maternal relatives in approximately one in seven forensic cases. Therefore, practitioners currently targeting the CR will still benefit greatly when choosing to implement the DCMPS approach, while deferring expansion of their analysis to the entire mtgenome.

The use of a DCMPS approach cannot be emphasized enough. Without sufficient depth of coverage at a nucleotide position, it is challenging to report heteroplasmy below the 10-20\% threshold typically reserved for STS. The majority (71\%) of the differentiating heteroplasmy in the current study was observed in the range of $2-10 \%$, highlighting the need for a low reporting threshold. Tissue specific considerations are also important when assessing the potential usefulness of differentiating heteroplasmy. In the current study, differentiating heteroplasmy was not considered unless observed in both buccal and blood cells. In a forensic case, hair shafts found at a crime scene are a common source of biological material for analysis, while the reference source from a suspect or victim is typically a buccal sample. Previous studies have illustrated that for direct comparison purposes, buccal samples are a better choice for the reference sample when working with hairs, as they originate from the same germ layer [6]. However, it may be important to collect both a buccal and blood sample from the reference source when differentiation of maternal relatives is being considered in a case. This would allow for an assessment of whether the heteroplasmy is random or potentially differentiating.

This is an exciting time in the development of MPS-based methods for the analysis of mtDNA in forensic cases. The use of a DCMPS approach will have a positive impact on the ability to solve more cases, and to enhance the weight of the findings. In addition, the analysis of low-level heteroplasmic variants will enhance the ability of clinicians to diagnose health-related conditions and provide counseling services to expecting parents. Along the way, further work will be needed to assess the drift of low-level heteroplasmic variants between tissue types and across generations, and to evaluate the impact of different MPS platforms on interpretation of the data. In addition, it would be valuable to develop enhanced methods of software alignment that may provide for a continuum of error assessments across nucleotide positions, perhaps allowing for the lowering of reporting thresholds for certain positions.

Supplementary Materials: The following are available online at www.mdpi.com/xxx/s1. Table S1: Haplotypes, haplogroups, and heteroplasmy for each of the 39 mother-child pairs. Heteroplasmy observed in buccal cell (Bu) and blood (Bl) samples. The frequency of shared heteroplasmy and sites of potential differentiating heteroplasmy are annotated as percentages (\%), Table S2: Sites of shared, differentiating, and random heteroplasmy for 29 of the 39 pairs; nine of the remaining 10 pairs exhibited no heteroplasmy, while the tenth pair had a shared, nine bp insertion. Read coverage and distribution, gene annotation and protein coding changes are provided. Sites of differentiating heteroplasmy in both buccal and blood cells are highlighted in BOLD text. A total of 16 of the 21 differentiating sites are in the coding region of the mtgenome, Table S3: Comparison of samples with differentiating heteroplasmy, shared heteroplasmy and random sites of heteroplasmy that are neither shared nor differentiating. No duplicate sites were observed within the datasets for differentiating and shared heteroplasmy, with one site (16093) observed in both the differentiating and shared datasets. A total of 28 of the 96 differentiating and shared sites ( $29 \%$, buccal and blood combined) have frequencies above $10 \%$. Each range of heteroplasmy is reported from blood $(\mathrm{Bl})$ to buccal $(\mathrm{Bu})$, not lowest to highest value.

Acknowledgments: The authors wish to thank Ian Paul (Department of Pediatrics, College of Medicine, Penn State University) for assistance with sample collection and Marcia Shu-Wei Su (Makova group) for assistance with sample processing. This work was supported in part by 2013-VFD-IR\&D-Task 5.3 from Battelle Memorial Institute (Assessment of mtDNA Heteroplasmy in Mother:Child Pairs Using a Next Generation DNA Sequencing Approach: Data Acquisition, Analysis and Storage Considerations), by 2014-DN-BX-K022 from the National Institute of Justice (NIJ), and by NIH R01GM116044 from the National Institutes of Health. The points of view are those of the authors and do not represent the official position or policies of the NIJ or U.S. Department of Justice.

Author Contributions: M.M.H. was involved with study design, data analysis, and manuscript preparation. K.D.M. was involved with study design and manuscript review. J.A.M. was involved with sample processing, data generation and analysis, and manuscript preparation.

Conflicts of Interest: The authors declare no conflict of interest. 


\section{References}

1. Stewart, J.B.; Chinnery, P.F. The dynamics of mitochondrial DNA heteroplasmy: Implications for human health and disease. Nat. Rev. Genet. 2015, 16, 530-542. [CrossRef] [PubMed]

2. Stefano, G.B.; Bjenning, C.; Wang, F.; Wang, N.; Kream, R.M. Mitochondrial Heteroplasmy. Mitochondrial Dynamics in Cardiovascular Medicine, Advances in Experimental Medicine and Biology; Santulli, G., Ed.; Springer International Publishing: Cham, Switzerland, 2017; Volume 982, pp. 577-594. [CrossRef]

3. Duggan, A.T.; Stoneking, M. A highly unstable recent mutation in human mtDNA. Am. J. Hum. Genet. 2013, 92, 279-284. [CrossRef] [PubMed]

4. Lopopolo, M.; Børsting, C.; Pereira, V.; Morling, N. A study of the peopling of Greenland using next generation sequencing of complete mitochondrial genomes. Am. J. Phys. Anthropol. 2016, 161, 698-704. [CrossRef] [PubMed]

5. Bodner, M.; Iuvaro, A.; Strobl, C.; Nagl, S.; Huber, G.; Pelotti, S.; Pettener, D.; Luiselli, D.; Parson, W. Helena, the hidden beauty: Resolving the most common West Eurasian mtDNA control region haplotype by massively parallel sequencing an Italian population sample. Forensic Sci. Int.-Genet. 2015, 15, 21-26. [CrossRef] [PubMed]

6. Gallimore, J.M.; McElhoe, J.A.; Holland, M.M. Assessing heteroplasmic variant drift in the mtDNA control region of human hairs using an MPS approach. Forensic Sci. Int.-Genet. 2018, 32, 7-17. [CrossRef] [PubMed]

7. Murphy, E.; Ardehali, H.; Balaban, R.S.; DiLisa, F.; Dorn, G.W., 2nd; Kitsis, R.N.; Otsu, K.; Ping, P.; Rizzuto, R.; Sack, M.N.; et al. Mitochondrial function, biology, and role in disease: A scientific statement from the American Heart Association. Circ. Res. 2016, 118, 1960-1991. [CrossRef] [PubMed]

8. Wallace, D.C. A mitochondrial bioenergetics etiology of disease. J. Clin. Investig. 2013, 123, 1406-1412. [CrossRef] [PubMed]

9. Santoro, A.; Balbi, V.; Balducci, E.; Pirazzini, C.; Rosini, F.; Tavano, F.; Achilli, A.; Siviero, P.; Minicuci, N.; Bellavista, E.; et al. Evidence for sub-haplogroup H5 of mitochondrial DNA as a risk factor for late onset Alzheimer's disease. PLoS ONE 2010, 5. [CrossRef] [PubMed]

10. Lièvre, A.; Chapusot, C.; Bouvier, A.M.; Zinzindohoué, F.; Piard, F.; Roignot, P.; Arnould, L.; Beaune, P.; Faivre, J.; Laurent-Puig, P. Clinical value of mitochondrial mutations in colorectal cancer. J. Clin. Oncol. 2005, 23, 3517-3525. [CrossRef] [PubMed]

11. Bratic, A.; Larsson, N.-G. The role of mitochondria in aging. J. Clin. Investig. 2013, 123, 951-957. [CrossRef] [PubMed]

12. Wallace, D.C.; Chalkia, D. Mitochondrial DNA genetics and the heteroplasmy conundrum in evolution and disease. Cold Spring Harb. Perspect. Biol. 2013, 3, 1-47. [CrossRef] [PubMed]

13. Rebolledo-Jaramillo, B.; Su, M.S.; Stoler, N.; McElhoe, J.A.; Dickins, B.; Blankenberg, D.; Korneliussen, T.S.; Chiaromonte, F.; Nielsen, R.; Holland, M.M.; et al. Maternal age effect and severe germ-line bottleneck in the inheritance of human mitochondrial DNA. Proc. Natl. Acad. Sci. USA 2014, 111, 15474-15479. [CrossRef] [PubMed]

14. Li, M.; Rothwell, R.; Vermaat, M.; Wachsmuth, M.; Schröder, R.; Laros, J.F.J.; van Oven, M.; de Bakker, P.I.W.; Bovenberg, J.A.; van Duijn, C.M.; et al. Transmission of human mtDNA heteroplasmy in the genome of the Netherlands families: Support for a variable-size bottleneck. Genome Res. 2016, 26, 417-426. [CrossRef] [PubMed]

15. Wilson, I.J.; Carling, P.J.; Alston, C.L.; Floros, V.I.; Pyle, A.; Hudson, G.; Sallevelt, S.C.E.H.; Lamperti, C.; Carelli, V.; Bindoff, L.A.; et al. Mitochondrial DNA sequence characteristics modulate the size of the genetic bottleneck. Hum. Mol. Genet. 2016, 25, 1031-1041. [CrossRef] [PubMed]

16. Ashley, M.V.; Laipis, P.J.; Hauswirth, W.W. Rapid segregation of heteroplasmic bovine mitochondria. Nuc. Acids Res. 1989, 17, 7325-7331. [CrossRef]

17. Ivanov, P.L.; Wadhams, M.J.; Roby, R.K.; Holland, M.M.; Weedn, V.W.; Parsons, T.J. Mitochondrial DNA sequence heteroplasmy in the Grand Duke of Russia Georgji Romanov establishes the authenticity of the remains of Tsar Nicholas II. Nat. Genet. 1996, 12, 417-420. [CrossRef] [PubMed]

18. Cree, L.M.; Samuels, D.C.; de Sousa Lopes, S.C.; Rajasimha, H.K.; Wonnapinij, P.; Mann, J.R.; Dahl, H.H.; Chinnery, P.F. A reduction of mitochondrial DNA molecules during embryogenesis explains the rapid segregation of genotypes. Nat. Genet. 2008, 40, 249-254. [CrossRef] [PubMed] 
19. Wonnapinij, P.; Chinnery, P.F.; Samuels, D.C. The distribution of mitochondrial DNA heteroplasmy due to random genetic drift. Am. J. Hum. Genet. 2008, 83, 582-593. [CrossRef] [PubMed]

20. Anderson, S.; Bankier, A.T.; Barrell, B.G.; de Bruijn, M.H.; Coulson, A.R.; Drouin, J.; Eperon, I.C.; Nierlich, D.P.; Roe, B.A.; Sanger, F.; et al. Sequence and organization of the human mitochondrial genome. Nature 1981, 290, 457-465. [CrossRef] [PubMed]

21. Gill, P.; Ivanov, P.L.; Kimpton, C.; Piercy, R.; Benson, N.; Tully, G.; Evett, I.; Hagelberg, E.; Sullivan, K. Identification of the remains of the Romanov family by DNA analysis. Nat. Genet. 1994, 6, 130-135. [CrossRef] [PubMed]

22. Irwin, J.A.; Saunier, J.L.; Niederstätter, H.; Strouss, K.M.; Sturk, K.A.; Diegoli, T.M.; Brandstätter, A.; Parson, W.; Parsons, T.J. Investigation of heteroplasmy in the human mitochondrial DNA control region: A synthesis of observations from more than 5000 global population samples. J. Mol. Evol. 2009, 68, 516-527. [CrossRef] [PubMed]

23. Parsons, T.J.; Muniec, D.S.; Sullivan, K.; Woodyatt, N.; Alliston-Greiner, R.; Wilson, M.R.; Berry, D.L.; Holland, K.A.; Weedn, V.W.; Gill, P.; et al. A high observed substitution rate in the human mitochondrial DNA control region. Nat Genet. 1997, 15, 363-368. [CrossRef] [PubMed]

24. Goto, H.; Dickins, B.; Afgan, E.; Paul, I.M.; Taylor, J.; Makova, K.D.; Nekrutenko, A. Dynamics of mitochondrial heteroplasmy in three families investigated via a repeatable re-sequencing study. Genome Biol. 2011, 12, R59. [CrossRef] [PubMed]

25. Pallotti, F.; Binelli, G.; Fabbri, R.; Valentino, M.L.; Vicenti, R.; Macciocca, M.; Cevoli, S.; Baruzzi, A.; DiMauro, S.; Carelli, V. A wide range of 3243A>G/tRNALeu(UUR) (MELAS) mutation loads may segregate in offspring through the female germline bottleneck. PLoS ONE 2014, 9, e96663. [CrossRef] [PubMed]

26. Cagnone, G.; Tsai, T.S.; Srirattana, K.; Rossello, F.; Powell, D.R.; Rohrer, G.; Cree, L.; Trounce, I.A.; St John, J.C. Segregation of naturally occurring mitochondrial DNA variants in a mini-pig model. Genetics 2016, 202, 931-944. [CrossRef] [PubMed]

27. Giuliani, C.; Barbieri, C.; Li, M.; Bucci, L.; Monti, D.; Passarino, G.; Luiselli, D.; Franceschi, C.; Stoneking, M.; Garagnani, P. Transmission from Centenarians to their offspring of mtDNA heteroplasmy revealed by ultra-deep sequencing. Aging 2014, 6, 454-467. [CrossRef] [PubMed]

28. Ma, K.; Zhao, X.; Li, H.; Cao, Y.; Li, W.; Ouyang, J.; Xie, L.; Liu, W. Massive parallel sequencing of mitochondrial DNA genomes from mother-child pairs using the Ion Torrent Personal Genome Machine (PGM). Forensic Sci. Int.-Genet. 2018, 32, 88-93. [CrossRef] [PubMed]

29. Li, M.; Schönberg, A.; Schaefer, M.; Schroeder, R.; Nasidze, I.; Stoneking, M. Detecting heteroplasmy from high-throughput sequencing of complete human mitochondrial DNA genomes. Am. J. Hum. Genet. 2010, 87, 237-249. [CrossRef] [PubMed]

30. Holland, M.M. Best practices for reporting mtDNA heteroplasmy when using an MPS approach: Considering rates, DNA damage \& drift. In Proceedings of the International Symposium on Human Identification, Minneapolis, MN, USA, September 2016.

31. McElhoe, J.A.; Holland, M.M.; Makova, K.D.; Su, M.S.; Paul, I.M.; Baker, C.H.; Faith, S.A.; Young, B. Development and assessment of an optimized next-generation DNA sequencing approach for the mtgenome using the Illumina MiSeq. Forensic Sci. Int.-Genet. 2014, 13, 20-29. [CrossRef] [PubMed]

32. Li, M.; Schröder, R.; Ni, S.; Madea, B.; Stoneking, M. Extensive tissue-related and allele-related mtDNA heteroplasmy suggests positive selection for somatic mutations. Proc. Natl. Acad. Sci. USA 2015, 112, 2491-2496. [CrossRef] [PubMed]

33. Tanaka, M.; Hayakawa, M.; Ozawa, T. Automated sequencing of mitochondrial DNA. Methods Enzymol. 1996, 264, 407-421. [CrossRef] [PubMed]

34. Andrews, R.M.; Kubacka, I.; Chinnery, P.F.; Lightowlers, R.N.; Turnbull, D.M.; Howell, N. Reanalysis and revision of the Cambridge reference sequence for human mitochondrial DNA. Nat. Genet. 1999, $23,147$. [CrossRef] [PubMed]

35. Holland, M.M.; Pack, E.; McElhoe, J.A. Evaluation of GeneMarker ${ }^{\circledR}$ HTS for improved alignment of mtDNA MPS data, haplotype determination, and heteroplasmy assessment. Forensic Sci. Int.-Genet. 2017, 28, 90-98. [CrossRef] [PubMed]

36. Li, H.; Durbin, R. Fast and accurate short read alignment with Burrows-Wheeler transform. Bioinformatics 2009, 25, 1754-1760. [CrossRef] [PubMed] 
37. Parson, W.; Gusmao, L.; Hares, D.R.; Irwin, J.A.; Mayr, W.R.; Morling, N.; Pokorak, E.; Prinz, M.; Salas, A.; Schneider, P.M.; et al. DNA Commission of the International Society for Forensic Genetics: Revised and extended guidelines for mitochondrial DNA typing. Forensic Sci. Int.-Genet. 2014, 13, 134-142. [CrossRef] [PubMed]

38. Bandelt, H.J.; Parson, W. Consistent treatment of length variants in the human mtDNA control region: A reappraisal. Int. J. Legal Med. 2008, 122, 11-21. [CrossRef] [PubMed]

39. Kircher, M.; Sawyer, S.; Meyer, M. Double indexing overcomes inaccuracies in multiplex sequencing on the Illumina platform. Nuc. Acids Res. 2012, 40, e3. [CrossRef] [PubMed]

40. Schirmer, M.; Ijaz, U.; D'Amore, R.; Hall, N.; Sloan, W.; Quince, C. Insight into biases and sequencing errors for amplicon sequencing with the Illumina MiSeq platform. Nuc. Acids Res. 2015, 43, e37. [CrossRef] [PubMed]

41. Bash [Unix shell program], 3.2.57(1) ed. Free Software Foundation: Boston, MA, USA, 2007.

42. Team R. RStudio: Integrated Development Environment for R, 0.99 .903 ed. RStudio, Inc.: Boston, MA, USA, 2015.

43. Fan, L.; Yao, Y.G. An update to MitoTool: Using a new scoring system for faster mtDNA haplogroup determination. Mitochondrion 2013, 13, 360-363. [CrossRef] [PubMed]

44. Van Oven, M.; Kayser, M. Updated comprehensive phylogenetic tree of global human mitochondrial DNA variation. Hum. Mutat. 2009, 30, E386-E394. [CrossRef] [PubMed]

45. Loman, N.; Misra, R.; Dallman, T.; Constantinidou, C.; Gharbia, S.; Wain, J.; Pallen, M.J. Performance comparison of benchtop high-throughput sequencing platforms. Nat. Biotech. 2012, 30, 434-439. [CrossRef] [PubMed]

46. May, A.; Abeln, S.; Buijs, M.J.; Heringa, J.; Crielaard, W.; Brandt, B.W. NGS-eval: NGS Error analysis and novel sequence VAriant detection tooL. Nuc. Acids Res. 2015, 43, W301-W305. [CrossRef] [PubMed]

47. Just, R.S.; Irwin, J.A.; Parson, W. DNA heteroplasmy in the emerging field of massively parallel sequencing. Forensic Sci. Int.-Genet. 2015, 18, 131-139. [CrossRef] [PubMed]

48. Li, M.; Stoneking, M. A New approach for detecting low-level mutations in next-generation sequence data. Genome Biol. 2012, 13, R34. [CrossRef] [PubMed]

49. Ross, M.; Russ, C.; Costello, M.; Hollinger, A.; Lennon, N.J.; Hegarty, R.; Nusbaum, C.; Jaffe, D.B. Characterizing and measuring bias in sequence data. Genome Biol. 2013, 14, R51. [CrossRef] [PubMed]

50. Quail, M.A.; Smith, M.; Coupland, P.; Otto, T.D.; Harris, S.R.; Connor, T.R.; Bertoni, A.; Swerdlow, H.P.; Gu, Y. A tale of three next generation sequencing platforms: Comparison of Ion Torrent, Pacific Biosciences and Illumina MiSeq sequencers. BMC Genom. 2012, 13, 341-354. [CrossRef] [PubMed]

51. Dohm, J.C.; Lottaz, C.; Borodina, T.; Himmelbauer, H. Substantial biases in ultra-short read data sets from high-throughput DNA sequencing. Nuc. Acids Res. 2008, 36, e105. [CrossRef] [PubMed]

52. Meacham, F.; Boffelli, D.; Dhahbi, J.; Martin, D.I.K.; Singer, M.; Pachter, L. Identification and correction of systematic error in high-throughput sequence data. BMC Bioinform. 2011, 12, 451-461. [CrossRef] [PubMed]

53. Nakamura, K.; Oshima, T.; Morimoto, T.; Ikeda, S.; Yoshikawa, H.; Shiwa, Y.; Ishikawa, S.; Linak, M.C.; Hirai, A.; Takahashi, H.; et al. Sequence-specific error profile of Illumina sequencers. Nuc. Acids Res. 2011, 39, e90. [CrossRef] [PubMed]

54. Minoche, A.E.; Dohm, J.C.; Himmelbauer, H. Evaluation of genomic high-throughput sequencing data generated on Illumina HiSeq and Genome Analyzer systems. Genome Biol. 2011, 12, R112. [CrossRef] [PubMed]

(C) 2018 by the authors. Licensee MDPI, Basel, Switzerland. This article is an open access article distributed under the terms and conditions of the Creative Commons Attribution (CC BY) license (http:/ / creativecommons.org/licenses/by/4.0/). 